\title{
ANTIOXIDANT DEFENSE SYSTEM IN SYMBIOTIC NODULES OF LEGUMES
}

\author{
(review)
}

\section{K.A. IVANOVA, V.E. TSYGANOV}

All-Russian Research Institute for Agricultural Microbiology, Federal Agency of Scientific Organizations, 3, sh. Podbel'skogo, St. Petersburg, 196608 Russia, e-mail tsyganov@arriam.spb.ru (corresponding author)

ORCID:

Ivanova K.A. orcid.org/0000-0002-9119-065X Tsyganov V.E. orcid.org/0000-0003-3105-8689

The authors declare no conflict of interests

Acknowledgements:

Supported financially by Russian Science Foundation (№ 14-04-00383) and by grant from President of the Russian Federation for leading scientific schools (HШ-6759.2016.4)

Received December 22, 2015

\begin{abstract}
Nitrogen-fixing nodules are formed on the roots of leguminous plants as a result of their interaction with soil bacteria, called rhizobia. Nodule development is based on the exchange of signaling molecules that leads to coordinated gene expression in both partners. This process is accompanied by differentiation of both plant and bacterial cells leading to formation of infected plant cells, filled with nitrogen-fixing forms of rhizobia, called bacteroids. The bacteroid is separated from the plant cell cytoplasm by the peribacteroid membrane and forms an organelle-like structure called the symbiosome (A.V. Tsyganova et al., 2017). The main function of the symbiotic nodule is to maintain the microaerophilic conditions required for working of the rhizobial nitrogen fixation enzyme nitrogenase, which is extremely sensitive to oxygen. Nitrogen-fixing nodules produce an abundance of reactive oxygen species (ROS) and reactive nitrogen species (RNS). These are formed due to auto-oxidation of leghemoglobin in the cytoplasm, oxidation of nitrogenase and ferredoxin in symbiosomes, and functioning of electron transport chains in mitochondria, symbiosomes, and peroxisomes (C. Chang et al., 2009). ROS and RNS molecules are involved in different signal transduction pathways; therefore, the nodule antioxidant system cannot simply eliminate ROS and RNS, but must maintain their concentration in the cell at the certain level (C.W. Ribeiro et al., 2015). Most antioxidants presented in plant organs are also found in the nodule, however, at a higher concentration, which is probably due to the high intensity of the processes associated with biological nitrogen fixation. These are enzymes superoxide dismutase, ascorbate peroxidase, glutathione peroxidase, and peroxiredoxins, as well as millimolar concentrations of non-enzymatic elements (primarily ascorbic acid and glutathione) (M. Becana et al., 2010). It has been discovered that Legumes harbor a unique homologue of glutathione, homoglutathione, both of which exhibit similar functions and specificity. However, it is still not clear why some Legumes evolved the ability to synthesize two different thiol compounds and require a double regulatory mechanism of the cell cycle including activation by glutathione and inhibition of cytokinesis by homoglutathione (T. Pasternak et al., 2014). It has now been shown that an increase in the level of glutathione leads to an increase in the efficiency of nitrogen fixation, while there is no similar data for homoglutathione. Considering that for the functioning of the nodule a balance in the ratio of glutathione and homoglutathione is necessary, it is evident that increasing the level of nitrogen fixation by modifying the levels of these thiols is a non-trivial task. Moreover, it is necessary to account for the influence of other components of the antioxidant system. It should be noted that the rhizobial antioxidants play an important role in the functioning of the nitrogen fixing nodule (C.W. Ribeiro et al., 2015). In this review, we will consider the main components of the plant antioxidant system in the nodule. A deeper understanding of its functioning is necessary to develop conditions for increasing the efficiency of biological nitrogen fixation.
\end{abstract}

Keywords: symbiotic nodule, antioxidants, redox potential, glutathione, homoglutathione, ascorbate, ascorbate-glutathione cycle, thiol peroxidases, redoxins, superoxide dismutase

Formation of a nitrogen-fixing nodule requires implementation of two specific developmental programs, one of which is responsible for its morphogenesis, and the other for formation of infection threads (tubular structures via which the rhizobia penetrate the root) $[1,2]$. In response to flavonoids secreted 
by legume plants, the rhizobia produce Nod factors (lipochitooligosaccharides from the $\mathrm{N}$-acetylglucosamine residues and fatty acid with different length and degree of unsaturation), which are recognized by plant LysM-receptor-like kinases [3]. Nod factors trigger both development programs; however, for their successful realization additional components are required [4].

Simultaneously with the development of infection threads, the nodule primordium is formed that is associated with mitotic reactivation, dedifferentiation and proliferation of cells [5]. In indeterminate nodules characterized by the presence of a stable apical meristem, the divisions occur in the inner cortex, root endodermis and pericycle [5]. The prolonged functioning of the meristem providing growth and constant renovation of nitrogen-fixing tissue leads to zone formation. Meristem, infection, nitrogen fixation and senescence zones can be distinguished in indeterminate nodule [6]. Only a limited number of evolutionally advanced legume plants from the sub-family of Papilionoideae, the tribes Trifolieae (clover, alfalfa) and Vicieae (pea, vetch) form indeterminate nodules. At the same time, in many papilionaceous plants, such as soybean, beans (Phaseoleae tribe) and deervetch (Loteae tribe), determinate nodules are formed from the cells of outer cortex with a meristem functioning for the limited period of time [6]. After its disappearance, the growth and renovation of nitrogen-fixing tissues cease, and zones are not identified in the central part of the nodule. The plant cells infected with rhizobia in indeterminate and determinate nodules pass through several endoreduplication cycles, which is accompanied by a significant increase in their sizes and resulted in cell susceptibility to filling with multiple bacteroids [7]. The differentiation of bacteroids in indeterminate nodules is a sequential process [8]; it is accompanied by the amplification of the entire genome and an increase in their sizes. Bacteria lose the ability to reproduce, i.e. their differentiation is irreversible. The bacteroids in the determinate nodules are comparable with free-living bacteria in the amount of genomic DNA, cell size and ability to reproduction [9].

Thus, nitrogen-fixing nodules are formed as a result of multistep differentiation of both symbiotic partners. At each of these steps, the redox cell balance plays a crucial role. Reactive oxygen species (ROS), reactive nitrogen species (RNS) and also the components of plant and bacterial antioxidant defense system are involved in maintaining of that balance in the nodule.

The principal value of the antioxidant defense system is determined, on the one hand, by the sensitivity of the nitrogenase, the main enzyme of atmospheric nitrogen fixation, to oxygen; and on the other hand, by multiple processes facilitating the formation of ROS and RNS in nitrogen-fixing systems. The synthesis of superoxide radical $\left(\mathrm{O}_{2}{ }^{\bullet-}\right)$ and hydrogen peroxide $\left(\mathrm{H}_{2} \mathrm{O}_{2}\right)$ is associated with high respiratory activity required for maintaining effective nitrogen fixation, autooxidation of oxygen-containing forms of leghemoglobin and oxidation of some proteins with high reductive potential (nitrogenase, ferredoxin, hydrogenase). Nitrogen monoxide (NO) is produced in infected cells of functioning nodules [10] by nitrate reductases of bacterial and plant origin [11, 12], and also due to plant NOsynthase activity [13]. Peroxynitrite $\left(\mathrm{ONOO}^{-}\right)$can be formed via reaction of $\mathrm{O}_{2}^{-}$ and NO. The antioxidants prevent development of oxidative and nitrosative stresses in the nodule, modulating the ROS and RNS concentrations and thus allowing them perform various functions in metabolism, including signal interactions during nodule formation [14-16].

Prevention of oxidative stress in plant cells is provided by a complex mechanism. Multiple enzymes such as ascorbate peroxidase, glutathione peroxidase (Gpx), catalase, peroxiredoxin (Prx), and superoxide dismutase (SOD) protect from prooxidants. The redox control of protein activity is carried out by thi- 
oredoxin (Trx) and glutaredoxin (Grx) [17, 18]. The non-enzymatic molecules, capable of acting as direct antioxidants, control the redox potential of the cell, thus affecting signal cascades, the cell cycle and the synthesis of various metabolites. Contrary to animal cells where the main non-enzymatic antioxidant is glutathione $(\mathrm{GSH})$, in plants ascorbate (ASC) executes the function of reducing hydrogen peroxide. However, GSH performs a number of unique functions in plant cells, which do not allow replacing it with another thiol or antioxidant [1921].

During formation of symbiosis the microsymbionts should also cope with the constantly oscillating contents of ROS and RNS. Rhizobia use different strategies in order to modulate the amount of these molecules, including inhibition of their synthesis and detoxication, and also controlling the activity of enzymes. During colonization and bacterial differentiation, a well-coordinated work of antioxidant systems of both partners is required to trigger the signal cascade activated by ROS and RNS. Not only successful development but also further functioning of the nodule depends on this balance. It has been shown that ROS also participate in the senescence of the micro- and macrosymbionts.

The aim of the present review was to generalize the modern views on the plant antioxidant system at different steps of rhizobium-legume symbiosis development and to highlight new components of this system. Special attention was paid to differences in the functions of glutathione and homoglutathione identified till now.

Non-enzymatic antioxidants. The positive correlation between the contents of GSH and ASC, the activity of enzymes participating in the ascorbate-glutathione cycle and the efficiency of nitrogen fixation in nodules suggests the importance of these antioxidants for nitrogen-fixing symbiosis [14, 23, 2629].

(Homo)glutathione. The thiol tripeptide GSH is a water soluble antioxidant and redox buffer of plants involved in cell cycle and processes of development, in sulfur transport and accumulation, in response to stress and detoxication of heavy metals [30]. GSH exists in cells in two main stable forms, as reduced and oxidized, the latter is glutathione disulfide (GSSG). Under optimal conditions, the ratio GSH:GSSG in most cellular compartments of the plant is fairly high. The sub-optimal external conditions lead to a shift of this ratio due to accumulation of GSSG which can cause alterations in acceptance and transduction of stress signals. In contrast to many other redox pairs (e.g. $\mathrm{NADP}^{+} / \mathrm{NADPH}$ ), in case of GSH and GSSG the redox potential of GSH depends not only on ratio of these forms, but also on absolute GSH concentration. Thus, even if the value of GSH:GSSG remains unchanged, a reduction in the concentration of GSH form leads to an increase in the redox potential [31].

The GSH synthesis comprises two ATP-dependent steps. The first limiting step of $\gamma$-Glu-Cys formation from glutamate and cysteine is catalyzed by $\gamma$ glutamylcysteine synthase ( $\gamma$-ECS), which is encoded by the GSH1 gene. The second step of GSH synthesis from $\gamma$-Glu-Cys and glycine is catalyzed by glutathione synthetase GSHS (GSHS gene). Homoglutathione (hGSH), GSH homologue wherein glycine is replaced with $\beta$-alanine, was found in the members of the $\mathrm{Fa}$ baceae family $[27,32,33]$. The synthesis of hGSH is carried out by homoglutathione synthetase (hGSHS) encoded by the hGSHS gene. The Arabidopsis GSH1 knockout mutant is lethal at the embryo stage [34], whereas knockout of the GSHS gene leads to seedling-lethal phenotype [35]. The subcellular fractionation and immunolocalization have shown that in nodules $\gamma$-ECS is present in plastids, whereas GSHS and hGSHS predominate in cytosol [36, 37]. However, no mutants knocked out only in one of the genes - hGSHS or GSHS among leg- 
ume plants have been obtained so far. This would allow determining the degree of interchangeability of these thiols and possible differences in their functions.

The substantial role of GSH and (or) hGSH in nodule formation was demonstrated for alfalfa (Medicago truncatula) using antisense constructs of $G S H S$ and $h G S H S$, and also via transcriptomic analysis of plants with a reduced content of (h)GSH as a result of treatment with L-buthionine-[S-R]sulfoximine, a specific inhibitor of (h)GSH biosynthesis. At the early stages of nodule formation in the plants with reduced synthesis of both thiols, there was an increase in the expression of genes controlled by salicylic acid [38]. The activation of these genes is, apparently, determined by redox-sensitive NPR1 protein that suppresses deformation of root hairs and expression of nodulins. The inactive NPR1, located in cytoplasm, is an oligomeric form resulted from reaction with S-nitrosoglutathione. The monomerization of NPR1, catalyzed by Trx, unmasks the signal motive of nuclear localization allowing for this protein to be transported in the nucleus wherein it interacts with redox-sensitive transcription factors [39]. Therefore, at the early stages of interaction, presence of a certain pool of (h)GSH in plant cells is the required for inhibiting the salicylateinduced defense mechanisms and colonization of plant host by rhizobia [40]. The reduction of the (h)GSH synthesis significantly decreased the number of nodules and suppressed the expression of the early nodulin genes (MtENOD12 and MtENOD40), which are gene markers of nodule formation. At the same time, both in control plants and in plants with reduced thiol level, no alterations were observed in the number of infection sites in the roots, which was confirmed by the similar expression of the Rip 1 gene, marker of infection process.

The inhibition of nodule formation was accompanied by a reduction in the number of the lateral roots [41]. It was shown that GSH is necessary for cell division in the root apex [42], and its amount controls the transition of cells from $G_{1}$ to $S$ phase of the cell cycle. The relocation of GSH to the nucleus at the $G_{1}$ phase strongly affects the redox state of the cytoplasm and expression of redox-sensitive genes. A further increase in the total cellular pool of GSH above the level observed in $G_{1}$ is required for transition of cell to the $S$ phase of the cycle [43, 44]. Apparently, exactly GSH stimulates the meristematic activity in nodules as well that correlates with maximum of GSH concentration in the meristem and in the infection zone of the nodule [45]. It is possible that the fluctuations of GSH pool in cytoplasm and in the nucleus may control the repetitive rounds of endoreduplication of infected cells and also the irreversible differentiation of bacteroids.

Using promoter of a gene, encoding cysteine-rich peptide (NCR001) specific for nitrogen fixation zone of the nodule, the role of the (h)GSH in mature nodules of $M$. truncatula was studied [46]. It was shown that the overexpression of the GSH1 in the nitrogen fixation zone led to an increase in the GSH but not the hGSH content that correlated with increase in the efficiency of nitrogen fixation. A decrease in the GSH1 gene expression by RNA interference reduce nitrogen fixation efficiency, (h)GSH content, nodule size, and expression of TrxS1 and LEG genes encoding Trx and leghemoglobin, respectively. In such nodules, the amount of the GSHS transcripts drastically increased compared to the control, whereas the expression of the $h G S H S$ gene did not change. Recently it was shown that $\operatorname{Tr} x S 1$ controls differentiation of bacteroids via the redox state of cysteine-rich peptide NCR335 [47]. Analysis of the spatial localization of transcripts revealed the expression of the GSH1 gene in the meristem, the infection zone and in the beginning of the nitrogen fixation zone, while expression of $h G S H S$ observed in the cortex and vascular bundles, and that of GSHS was in 
the cortex and in the nitrogen fixation zone. This further confirms the important role of GSH for functioning of meristematic and nitrogen fixing cells and differentiation of cells in the infection zone. Also it is likely that in the cortical cells both thiols play an important role in maintaining the oxygen barrier of the nodule [46].

In 73 species of 3 subfamilies, the distribution of (h)GSH in the Fabaceae family was studied [48]. It was shown that hGSH was absent in the members of Caesalpinioideae subfamily, but it was found in two species of Mimosoideae and in species of the Old World clade in Papilionoideae subfamily. Distribution of (h)GSH was tissue-specific. The hGSH content was often higher in leaves and roots, the GSH in seeds, which can reflect a difference in the functions of both thiols. At the same time, in the species forming and not forming nitrogenfixing nodules, the distribution of hGSH did not change; therefore, the accumulation of hGSH in the roots probably is not related to nodule formation [48].

Previously in M. sativa it was shown that GSH is associated with meristematic cells, activation of the cell cycle and induction of somatic embryogenesis, whereas hGSH is associated with differentiated cells and embryo proliferation. Thus, the ratio of hGSH:GSH was the lowest in the root meristem and the highest in the fully differentiated organs (mature leaves and root elongation zone). It supposed that alterations in hGSH/GSH occur during dedifferentiation and (or) activation of the cell cycle that leads to transition from differentiated to dividing cells [49]. As already noted, these processes take place during formation of the nodule primordium. In M. sativa, in the formed nodules, as compared to leaves and roots, GSH becomes the main thiol compound. Alterations in the thiol ratio are reversible: in the cell culture after development of somatic embryos and cell differentiation, the ratio of hGSH:GSH increased again, and in the nodules the hGSH content grew as the tissues differentiated [45]. Probably, local alterations in amounts of phytohormones, associated with developmental programs and (or) environmental influence, could regulate (h) GSHS expression or (h)GSHS activity and therefore lead to the observed patterns of hGSH and GSH distribution.

Indeed, the expression of the GSHS and $h G S H S$ genes not only strongly varies depending on the species and tissue of legume plant, but is also regulated differently in response to signal molecules or stress conditions. E.g. in M. truncatula the $h G S H S$ expression can be detected in roots and nodules, and that of GSHS is found in all plant tissues [50]. Moreover, in the roots of M. truncatula the expression of the GSH1 and GSHS, but not $h G S H S$ is induced by nitrogen oxide [51]. In deervetch (Lotus japonicus) GSHS is found in nodules only, and hGSHS is present in leaves and roots as well [33]. In the roots of L. japonicus GSHS is activated by auxins, cytokinins and polyamines, whereas the expression of $h G S H S$ remains unchanged [14]. The addition of exogenous hydrogen peroxide induced increase the expression of the GSH1 and $h G S H S$ genes in beans nodules, whereas $\mathrm{CdCl}_{2}, \mathrm{NaCl}$ or jasmonic acid did not cause such an effect [52]. Long-term treatment with cadmium chloride of pea (Pisum sativum) mutant SGECd ${ }^{t}$ [53] resistant to cadmium a slight decrease in the expression of GSH1 and GSHS genes was observed, whereas the expression of $h G S H S$ increased in the roots of the mutant and wild type plants [54]. The analysis of the obtained data suggests the presence of specific cis-regulatory elements in the promoter region of $G S H S$ and $h G S H S$ genes and (or) different regulatory mechanisms for GSHS and $h G S H S[14]$.

The synergism of phytohormones and oxidative stress plays an important role in the control of plant growth and development [55], and GSH and hGSG may mediate such control in legume plants. Nodule formation is an energy con- 
suming process. Integration of oxidative stress metabolism and cell cycle allows avoiding unwanted energy expenses by separating defense mechanisms from the processes of cell division and differentiation.

Thus, an important role of (h)GSH in development and functioning of symbiotic nodules has been identified. Nevertheless, the specificity of action of GSH and hGSH in nodule tissues and at the different stages of its development remains insufficiently studied. A lot of data has been obtained by analysis of only one plant species. In addition, a significant difference is observed between species forming indeterminate (Table 1) and determinate (Table 2) nodules.

1. Synthesis and distribution of glutathione GSH and homoglutathione (h)GSH in organs and tissues of the nodule in legume plants forming indeterminate nodules $[36,45-46,48,50,89]$

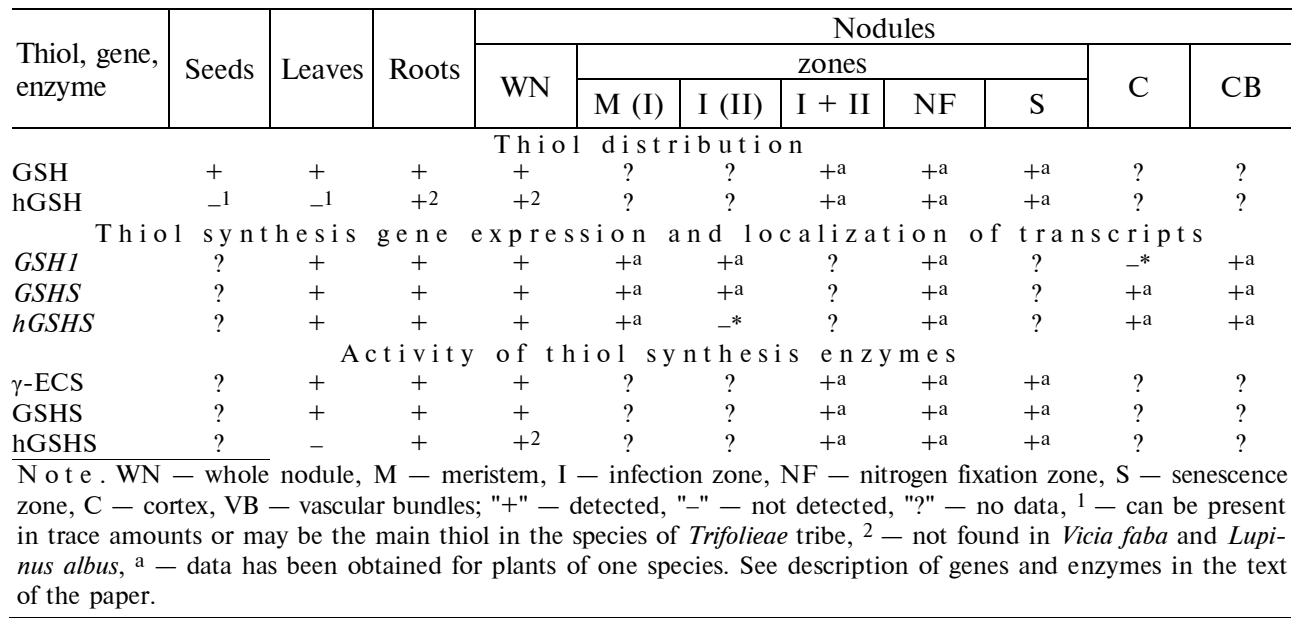

2. Synthesis and distribution of glutathione GSH and homoglutathione (h)GSH in organs and tissues of nodules in legume plants forming determinate nodules [27, $36,45,48,89,91]$

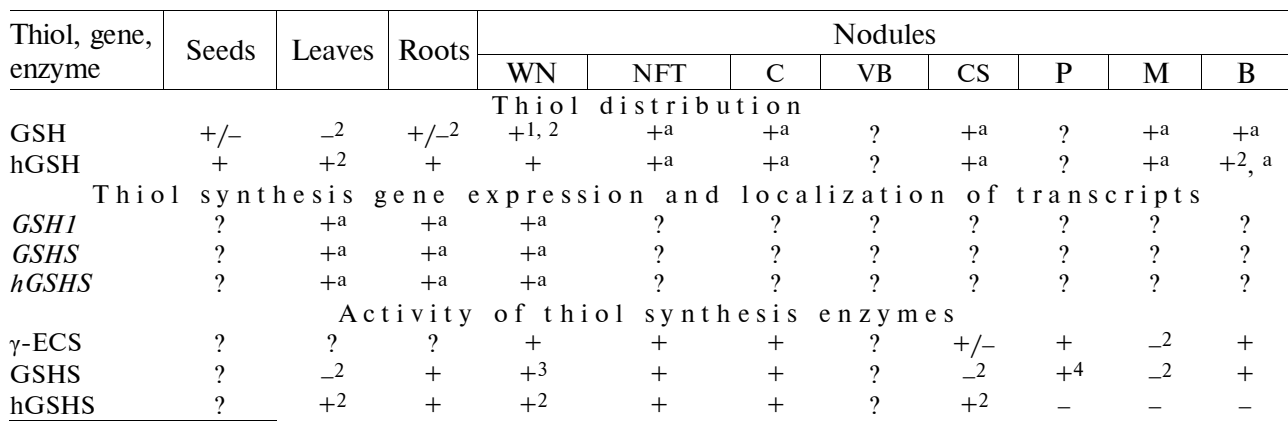

N o t e. WN - whole nodule, NFT - nitrogen-fixing tissue, C - cortex, VB - vascular bundles, CS - cytosol, $\mathrm{P}$ - plastids, $\mathrm{M}$ - mitochondria, B - bacteroids; "+" - detected, "-" - not detected, "+/-" - trace amounts, "?" - no data.

1 - GSH of bacterial origin, ${ }^{2}-$ except for Vigna unguiculata, ${ }^{3}-$ except for Vigna radiata, ${ }^{4}-$ contamination from bacteroids,

a - data has been obtained for plants of one species. See description of genes and enzymes in the text of the paper.

There are differences and between the species forming the same type of nodules (see Tables 2, 3). Nevertheless, some patterns can be observed. Thus, indeterminate nodules mostly contain GSH as the main soluble tripeptide whereas hGSH is the most widespread tripeptide in determinate nodules [45].

Ascorbic acid. This is a powerful soluble antioxidant acting directly and as a part of the ascorbate-glutathione cycle. Ascorbic acid is present at a concentra- 
tion of 1 to $2 \mathrm{mM}$ in nodules [56], 5 to $25 \mathrm{mM}$ in leaves, and 25 to $50 \mathrm{mM}$ in chloroplasts [57] that is consistent with its multiple important functions. The

3. Synthesis and distribution of glutathione GSH and homoglutathione (h)GSH in organs and mitochondria of Vigna unguiculata, forming determinate nodules $[36,45]$

\begin{tabular}{|c|c|c|c|c|}
\hline $\begin{array}{l}\text { Thiol, } \\
\text { enzyme }\end{array}$ & Leaves & Roots & Nodules & Mitochondria \\
\hline \multicolumn{5}{|c|}{ Thiol distribution } \\
\hline GSH & + & + & + & $?$ \\
\hline hGSH & - & + & $+/-$ & $?$ \\
\hline \multicolumn{2}{|c|}{ Activity } & t h i o 1 & synthesis & e $n z y m e s$ \\
\hline$\gamma$-ECS & $?$ & $?$ & + & + \\
\hline GSHS & + & + & + & + \\
\hline hGSHS & - & + & - & - \\
\hline \multicolumn{5}{|c|}{$\begin{array}{l}\text { N o t e. "+" }- \text { detected, "-" }- \text { not detected, "+/-" }- \text { trace } \\
\text { amounts, "?" }- \text { no data. See description of enzymes in the text of } \\
\text { the paper. }\end{array}$} \\
\hline
\end{tabular}

redox state of ASC (ASC + dehydroascorbic acid) controls the cell cycle [58] and plays a crucial role in perception of stress signals in the apoplast and their transduction into cytoplasm. ASC is also a cosubstrate for several dioxygenases participating in hydroxylation of proline and biosynthesis of flavonoids and hormones, i.e. ethylene, gibberellic, and abscisic acids [59]. The importance of ASC for plants is confirmed by the absence of known mutants that are completely defective in ASC synthesis [60]. ASC is mainly synthesized via the D-mannose/D-galactose (Smirnoff-Wheeler) pathway comprising multiple and complex enzymatic reactions, and final reactions is catalyzed by mitochondrial L-galactono-1,4-lactone dehydrogenase [61].

Investigation of $P$. sativum showed that ASC content decreases in nodules with age, that correlating with a decrease in the GSH content and nitrogenase activity [23]. It was supposed that ASC is not synthesized de novo in nodules but is imported from shoots or roots through the vascular system [23]. However, later it was shown that ASC biosynthesis genes, including GalLDH gene encoding L-galactono-1,4-lactone dehydrogenase, are expressed in the nodules of $L$. japonicus. The active enzyme is localized in the mitochondria of beans (Phaseolus vulgaris). Investigation of nodules of four legume species: alfalfa $(M$. sativa), pea ( $P$. sativum), beans ( $P$. vulgaris) and deervetch ( $L$. japonicus), showed an increased activity of L-galactono-1,4-lactone dehydrogenase and cytosol ascorbate peroxidase, but also the decreased ASC level in nodules compared to other plant parts [62]. Using FISH, it was shown that mRNA of GalLDH is predominantly located in cells of nitrogen fixation zone in the nodules of $M$. sativa and in nitrogen-fixing cells of the central part of the nodule in L. japonicus. Also, the maximum content of L-galactono-1,4-lactone dehydrogenase and ASC was found in these cells. At the same time, the enzyme activity was the same in the apex (meristem and infection zone) and in the nitrogen fixation zone, whereas amounts of mRNA were different, that indicates the post-translation regulation [62]. The presence of post-transcription regulation is evidenced by the fact that under the stress condition (treatment with cadmium salts, $\mathrm{NaCl}$, hydrogen peroxide and jasmonic acid), the ASC content changed but the activity of L-galactono-1,4lactone dehydrogenase remained unchanged in bean nodules [52]. The ageing of symbiotic nodules is possibly accompanied by switching off the ASC biosynthesis that is confirmed by a reduction in the L-galactono-1,4-lactone dehydrogenase activity and ASC content.

The ASC concentration in cells is regulated by a degree of its oxidation and degradation. ASC oxidizes to monodehydroascorbic acid or dehydroascorbic acid during hydrogen peroxide detoxication via ascorbate-glutathione cycle in cytosol, chloroplasts and other organelles. In the apoplast, ASC is oxidized to monodehydroascorbic acid by ascorbate oxidase [63]. The treatment of the bean plants with jasmonic acid, a well-known stress-associated compound, led to translational activation of ascorbate oxidase and post-translational inhibition of dehydroascorbate reductase in nodules that possibly enhances oxidations in apo- 
plast and initiates a signal via which nodules may perceive stress and respond to it [52].

Enzymatic antioxidants. Ascorbate-glutathione cycle. Ascorbate peroxidase, monodehydroascorbate reductase, dehydroascorbate reductase and glutathione reductase participate in this cycle. The regulation of subcellular isoforms each of these enzymes, which have been found in cytosol, plastids, mitochondria, and peroxisomes, is carried out based on the level of ASC and GSH synthesis in these organelles under normal and stress conditions. Each isoform can differently respond to signals associated with stress or developmental process. The regulation of all isoforms of enzymes participated in the ascorbateglutathione cycle is quite important for maintaining the redox balance in the plant cells under abiotic and biotic stresses [64].

In the nodules, the ascorbate-glutathione pathway was found 30 years ago [56]. Later, the comparison of activity was carried out for enzymes involved in this pathway in the nodules of soybean (Glycine max), formed on three genotypes by effective and ineffective strains. The same analysis was carried out for nodules of wild type and ineffective mutant genotypes of $M$. sativa [26]. High activity in effective nodules was demonstrated for all four enzymes (ascorbate peroxidase, monodehydroascorbate reductase, dehydroascorbate reductase, and glutathione reductase) in both studied species. Also, in effective nodules GSH and hGSH content was higher compared with ineffective ones. At the same time, no such correlation was observed for ASC. Transcriptomic analysis revealed increased expression of genes encoding the enzymes of the ascorbateglutathione pathway in nodules [65]. Therefore, the ascorbate-glutathione pathway is one of the main mechanisms of their antioxidant defense [26].

In the ascorbate-glutathione pathway, GSSG is formed from GSH that leads to the change in the GSH:GSSG ratio. Some other metabolic pathways can also link the availability of oxidants and alterations in the GSH:GSSG ratio, thus, affecting the signaling transduction via regulation of thiol-disulfide status of the proteins. The key participants of these reactions are Prx, Gpx, Trx and Grx. Some glutathione S-transferases (GST) can also use GSH for reduction of organic hydroperoxides, and others can generate GSSG, possibly, catalyzing the deglutathionylation cysteine residues of proteins [66]. The role of these processes in the formation and functioning of nitrogen-fixing nodule is still insufficiently studied.

Thiol peroxidases and redoxins. Thiol peroxidases ( $\mathrm{Gpx}$ and $\operatorname{Prx}$ ) are small proteins without gem, catalyzing reduction of the $\mathrm{H}_{2} \mathrm{O}_{2}$ or alkyl hydroperoxides $(\mathrm{ROOH})$ to water or corresponding alcohols $(\mathrm{ROH})$ using mostly Trx as electron donors. Trx contains a conservative interaction site (Try-Cys-Gly-ProCys) which reduce disulfide bridges of the target proteins [67]. Grx, with functions similar to Trx, can also act as electron donor; GSH is used for its reduction [21]. Gpx, Prx and Trx are encoded by multigene families, and the corresponding isoforms have different subcellular localization (cytosol, plastids and mitochondria) [14].

In L. japonicus, six genes were identified to encode Gpx. Two of these, LjGpx 1 and LjGpx3, encoding Trx-dependent hydroperoxidases, are actively expressed in nodules. Immunolocalization showed the presence of Gpx around the starch granules in amyloplasts in infected and non-infected cells of $L$. japonicus nodules, and in infected cell of $M$. sativa nodules that may indicate formation of hydrogen peroxide in amyloplasts as well [68]. Later, using in situ hybridization, a high content of mRNA was shown in infection zone for LjGpx 1 and LjGpx3 and in nodule cortical cells for the LjGpx3 as well. Immunolocalization detected LjGpx1 in amyloplasts and in nuclei of infected cells, in cortical cells and in vas- 
cular bundles. LjGpx3 was predominantly located in endoplasmic reticulum (ER), cytosol and nuclei [69[. Conclusion, that LjGpx1 and LjGpx3 protect cells from oxidative and salt stresses and membrane damage, was made basing on complementation experiments with yeasts.

PrxIIA (the cytosol isoform of Prx), the amount of which is reduced with nodule age, and mitochondrial isoform PrxIIF, the amount of which does not change were identified in the nodules of $P$. sativum. After exogenous treatment with ASC, the PrxIIA level decreased in young nodules and increased in old ones, the amount of PrxIIF was unchanged in both cases [70]. In $M$. truncatula, L. japonicus and P. vulgaris, the proteomic analysis of nodules identified PrxIIB, PrxIIE and PrxIIF isoforms ( $\mathrm{B}$ in cytosol, $\mathrm{E}$ in plastids, and $\mathrm{F}$ in mitochondria), a cytosol isoform Trxh1, and also GrxC2 and GrxC4, which possibly can serve as electron donors for Prx. Moreover, NADPH-thioredoxin reductases (NTRA/B/C) were found in nodules of these legumes. Most of these Prx isoforms are effectively reduced by Trx and non-plastid Trx is recovered by NTRA and NTRB. The obtained data confirm the presence of this redox regulator network in cytosol, plastids and mitochondria of nodule cells (cytosol forms of PrxIIB, Trxh1 and NTRA are most active).

In M. truncatula, two new isoforms of Trx (Trxs), functioning during symbiotic interactions, were found [71]. These ER-addressed Trx are similar to classic ones, but have atypical catalytic sites. In silico, using the atlas of $M$. truncatula gene expression in different organs and under various growth conditions, it was shown that $\operatorname{Trxs} 1$ is mostly expressed during nodule formation, whereas $\operatorname{Tr} x s 2$ expression is apparently less specific $[65,72]$. The analysis of the spatial localization of Trxs1 and expression of Trxs2, using https://iant.toulouse.inra.fr/symbimics/ resource, which gives access to results of laser microdissection of $M$. truncatula nodules combined with RNA sequencing, has shown that these $\operatorname{Tr} x$ are mostly expressed in the infection zone [73]. The expression pattern of Trxs indicates their participation in the development of nodule and cell differentiation in the infection zone. In situ hybridization revealed the presence of $G m T r x$ mRNA in the root pericycle of $G$. $\max$ in 2 days post inoculation and in the infected cells of mature 27-dayold nodules. The transformation of the Trx-defective yeast mutant with the $G m \operatorname{Tr} x$ gene recovered tolerance to exogenous $\mathrm{H}_{2} \mathrm{O}_{2}$. RNA interference of $G m \operatorname{Tr} x$ led to the absence of nodules or formation of undeveloped nodules that indicates the importance of this gene in their development [74].

Glutathione-S-transferases. These widely distributed enzymes participating in detoxication of xenobiotics, especially herbicides. GSTs act as antioxidants as well, directly trapping peroxides like Gpx. The final products of the peroxide oxidation of lipids alkenals, 4-hydroxynonenal and other $\alpha$ - and $\beta$-unsaturated aldehydes, may be removed after conjugation with GSH [75, 76]. In soybean, GSTs are encoded by a multigene family of 25 genes [77]. In the nodules, the expression of 14 GST isoforms was found; gene encoding GST9 showed maximum level of expression [76]. The suppression of the GST9 expression by RNA interference significantly decreased the nitrogenase activity in the nodules [76].

Superoxide dismutases (SODs). SODs belong to the group of metal containing enzymes, catalyzing dismutation of superoxide radical to hydrogen peroxide and molecular oxygen. Depending on metal cofactors, there are $\mathrm{Fe}-\mathrm{Mn}$ CuZn-dependent SODs (correspondingly FeSOD, MnSOD and CuZnSOD). All of these SODs are present in nodules, but with different subcellular localization.

In indeterminate nodules of $M$. sativa and $P$. sativum, the transcripts of the cytosol CuZnSOD, as well as the enzyme itself, are present predominantly in the meristem, the infection zone and distal part of the nitrogen fixation zone 
[78]. CuZnSOD was localized in the cytosol in the regions adjacent to cell walls, to the walls of infection threads, and also in the matrix of infection threads. Moreover, the enzyme was found in the intracellular spaces of the cortical cells and cells in the nitrogen fixation zone. The transcripts of MnSOD and the enzyme itself were localized predominantly in the nitrogen fixation zone. The enzyme was present in bacteria inside the infection threads, in bacteroids and mitochondria. In the nodules, the co-localization of $\mathrm{H}_{2} \mathrm{O}_{2}$ with $\mathrm{CuZnSOD}$ was found, but not with $\mathrm{MnSOD}$, i.e. exactly CuZnSOD is one of the most important $\mathrm{H}_{2} \mathrm{O}_{2}$ sources in nodules [56] and possibly plays an important role in forming matrix of infection threads and their growth [79]. Later, the transcriptome analysis of $M$. truncatula nodules has shown that the genes encoding CuZnSOD isoforms and mitochondrial MnSOD are actively expressed in nodules whereas expression of the gene for cytosol FeSOD remains relatively low [65].

In determinate nodules of L. japonicus, the expression of genes of cytosol $\mathrm{CuZnSOD}$ and mitochondrial MnSOD, as well as the amount and activity of the enzymes reduced with age. In the young nodules, CuZnSOD is found in dividing cells, in infection threads and in infected cells. The transcription of FeSOD2 which encodes cytosol FeSOD activated and that of FeSOD1 encoding plastid FeSOD did not change. With nodule age, the amount and activity of FeSOD increased. At all stages of nodule development, this enzyme was present predominantly in the amyloplasts in the cortical cells, uninfected and infected cells. It was supposed that two cytosol enzymes, CuZnSOD and FeSOD2, are capable to functionally compensate each other at later stages of nodule development. Induction of FeSOD2 is possibly associated with an increase in $\mathrm{Fe}$ availability in the senescent nodules, possibly as a result of leghemoglobin degradation [80].

Under salt stress, the total activity of SOD in the nodules of $P$. vulgaris increased [81]; the activity of FeSOD also enhanced, and the activity of CuZnSOD and MnSOD did not change [82]. In the peanut plants under draught, the amount of CuZnSOD transcripts in the nodules increased whereas the activity of SOD, MnSOD I and MnSOD II did not change [83]. The opposite results were obtained for SOD in $P$. sativum and $G$. max nodules at draught, when total SOD activity decreased in $P$. sativum and increased in $G$. $\max [84,85]$. Such diverse responses of various species stress out a necessity of studying the gene expression and regulation of enzyme activity in more detail.

Catalases. These are tetrameric gem proteins catalyzing the decomposition of hydrogen peroxide to molecular oxygen and water, which are predominantly localized in peroxisomes and glyoxysomes [86]. An important role of rhizobial catalases has been shown for development of effective symbiosis [87]; however, the enzymes of plant origin have been insufficiently studied. In the nodules of white lupine (Lupinus albus), the catalase was localized in the peroxisomes of infected cells, and its concentration was reduced during nitrate-induced senescence [88]. Also, the enzyme activity reduced in bean nodules under salt stress [82].

Thus, over 30-year studying antioxidant system of nitrogen-fixing nodules in legumes, a significant progress was achieved. The principles of operation and interaction of antioxidant molecules, enzymes and redox regulatory pathways during the processes of initiation, development and functioning of legumerhizobium symbiosis were analyzed. The complexity and ambiguity of the functioning of the antioxidant system were identified. To date, it was shown that GSSH participates in signal transduction via alteration of the redox state of the cell and its compartments. This, in its turn, may control the thiol-disulfide status of proteins, i.e. the conformation and activity of enzymes and transcription factors directly or via thiol-dependent peroxidases. Moreover, the oxidation of some 
thiol-dependent peroxidases can itself serve as a signal or signal trigger. In 1988, the distribution of GSH and hGSH in plant tissues of 13 Fabaceae species from various tribes was analyzed [89]. In the following years, a lot of data was accumulated indicating specific functioning of these thiols, including that among species forming determinate and indeterminate nodules. In 2015, the distribution of GSH and hGSH has been analyzed already in 73 species of three Fabaceae sub-families [48]; however, the question of the GSH and hGSH specific functions still remains open. At the same time, the role of GSH in the development and functioning of meristem cells and nitrogen-fixing cells has been proven. Moreover, it was demonstrated that the ratio of hGSH and GSH may activate cell differentiation and dedifferentiation [49]. Data about new components of antioxidant defense in nodules continue to appear, e.g. polyamines, the polycationic compounds capable of modulating concentrations of ROS and RNS, were described. However, the role of these molecules in the functioning and development of nodules requires further studies [90].

Thus, the redox state of a cell and its compartments, determined by the pro- and antioxidant ratio and interaction, controls a variety of processes via changing oxidation/reduction balance under the influence of environmental signals and participating in their transduction and subsequent plant responses. The antioxidant system plays a crucial role in formation and functioning of such a sensitive system as a nitrogen-fixing nodule of legume plants characterized by active metabolism and constant exchange of signal molecules between partners.

\section{REFERENCES}

1. Guine 1 F.C., G e i 1 R.D. A model for the development of the rhizobial and arbuscular mycorrhizal symbioses in legumes and its use to understand the roles of ethylene in the establishment of these two symbioses. Can. J. Bot., 2002, 80(7): 695-720 (doi: 10.1139/b02-066).

2. Tsyganov V.E., Voroshilova V.A., Priefer U.B., Borisov A.Y., Tikhono$\mathrm{v}$ i c h I.A. Genetic dissection of the initiation of the infection process and nodule tissue development in the Rhizobium-pea (Pisum sativum L.) symbiosis. Ann. Bot., 2002, 89(4): 357-366 (doi: 10.1093/aob/mcf051).

3. P o p p C., O t t T. Regulation of signal transduction and bacterial infection during root nodule symbiosis. Curr. Opin. Plant Biol., 2011, 14(4): 458-467 (doi: 10.1016/j.pbi.2011.03.016).

4. Kawaharada Y., Kelly S., Nielsen M.W., Hjuler C.T., Gysel K., Muszyński A., Carlson R.W., Thygese n M.B., Sandal N., Asmussen M.H., Vinther M., Andersen S.U., Krusell L., Thirup S., Jensen K.J., Ronson C.W., Blaise M., Radutoiu S., S touga ard J. Receptor-mediated exopolysaccharide perception controls bacterial infection. Nature, 2015, 523: 308-312 (doi: 10.1038/nature14611).

5. Tsyga nova A.V., Kit a eva A.B., B revi n N.Dzh., Ts y ga nov V.E. Cellular mechanisms of nodule development in legume plants. Sel'skokhozyaistvennaya biologiya [Agricultural Biology], 2011, 3: 34-40 (in Russ.).

6. Guine 1 F.C. Getting around the legume nodule: I. The structure of the peripheral zone in four nodule types. Botany, 2009, 87: 1117-1138 (doi: 10.1139/B09-074).

7. Tsyganova A.V., Kitaeva A.B., Tsyganov V.E. Cell differentiation in nitrogenfixing nodules hosting symbiosomes. Funct. Plant Biol., 2017 (doi: 10.1071/FP16377).

8. Tsyganov V.E., Voroshilova V.A., Herrera-Cervera J.A., Sanjuan-Pinilla J.M., Borisov A.Y., Tikhonovich I.A., Priefer U.B., Olivares J., Sanjuan J. Developmental downregulation of rhizobial genes as a function of symbiosome differentiation in symbiotic root nodules of Pisum sativum. New Phytol., 2003, 159: 521-530 (doi: 10.1046/j.14698137.2003.00823.x).

9. Mergaert P., Uchiumi T., Alunni B., Evanno G., Cheron A., Catrice O., Mausset A.E., Barloy-Hubler F., Galibert F., Kondorosi A., Kondorosi E. Eukaryotic control on bacterial cell cycle and differentiation in the Rhizobium-legume symbiosis. PNAS USA, 2006, 103(13): 5230-5235 (doi: 10.1073/pnas.0600912103).

10. Baudouin E., Pieuchot L., Engler G., Pauly N., Puppo A. Nitric oxide is formed in Medicago truncatula-Sinorhizobium meliloti functional nodules. Mol. Plant-Microbe Interact., 2006, 19: 970-975 (doi: 10.1094/MPMI-19-0970).

11. Meakin G.E., Bueno E., Jep son B., Bed mar E.J., Richardson D.J., De 1$\mathrm{g}$ a d o M.J. The contribution of bacteroidal nitrate and nitrite reduction to the formation of nitrosylleghaemoglobin complexes in soybean root nodules. Microbiology, 2007, 153: 411-419 (doi: 
10.1099/mic.0.2006/000059-0).

12. Horchani F., Prévot M., Boscari A., Evangelisti E., Meilhoc E., Bru and C., Raymond P., Boncompagni E., Aschi-Smiti S., Puppo A., Brou$\mathrm{qu}$ is s e R. Both plant and bacterial nitrate reductases contribute to nitric oxide production in Medicago truncatula nitrogen-fixing nodules. Plant Physiol., 2011, 155(2): 1023-1036 (doi: 10.1104/pp.110.166140).

13. Cueto M., Hernánd e z-Perera O., Martín R., Bentura M.L., Rodrigo J., La mas S., Golva no M.P. Presence of nitric oxide synthase activity in roots and nodules of Lupinus albus. FEBS Lett., 1996, 398(2-3): 159-164 (doi: 10.1016/s0014-5793(96)01232-x).

14. B e cana M., Mat a moros M.A., Udvardi M., Dalton D.A. Recent insights into antioxidant defenses of legume root nodules. New Phytol., 2010, 188(4): 960-976 (doi: 10.1111/j.1469-8137.2010.03512.x).

15. Ribeiro C.W., Allo ing G., Mandon K., Frendo P. Redox regulation of differentiation in symbiotic nitrogen fixation. Biochim. Biophys. Acta, 2015, 1850(8): 1469-1478 (doi: 10.1016/j.bbagen.2014.11.018).

16. Damiani I., Pauly N., Puppo A., B rouquisse R., Boscari A. Reactive oxygen species and nitric oxide control early steps of the Legume - Rhizobium symbiotic interaction. Front. Plant Sci., 2016, 7 (doi: 10.3389/fpls.2016.00454).

17. Meyer Y., Buchanan B.B., Vignols F., Reichheld J.P. Thioredoxins and glutaredoxins: unifying elements in redox biology. Annu. Rev. Genet., 2009, 43: 335-367 (doi: 10.1146/annurev-genet-102108-134201).

18. Meyer Y., B elin C., Delorme-Hinoux V., Reichheld J.P., Riondet C. Thioredoxin and glutaredoxin systems in plants: molecular mechanisms, crosstalks, and functional significance. Antiox. Redox. Signal., 2012, 17: 1124-1160 (doi: 10.1089/ars.2011.4327).

19. Ge st N., G a u ti e r H., S t e ve n s R. Ascorbate as seen through plant evolution: the rise of a successful molecule? J. Exp. Bot., 2013, 64: 33-53 (doi: 10.1093/jxb/ers297).

20. Foyer C.H., Noctor G. Ascorbate and glutathione: the heart of the redox hub. Plant Physiol., 2012, 155: 2-18 (doi: 10.1104/pp.110.167569).

21. Noctor G., Mhamdi A., Chaouch S., Han Y., Neukermans J., MarquezG a r c i a B., Q u e v a 1 G., F o y e r C.H. Glutathione in plants: an integrated overview. Plant Cell Environ., 2012, 35: 454-484 (doi: 10.1111/j.1365-3040.2011.02400.x).

22. Harrison J., Jamet A., Muglia C.I., Van de Sype G., Aguilar O.M., Pup p o A., Fre nd o P. Glutathione plays a functional role in growth and symbiotic capacity of Sinorhizobium meliloti. J. Bacteriol., 2005, 187: 168-174 (doi: 10.1128/JB.187.1.168-174.2005).

23. Groten K., Vanacker H., Dutilleul C., B astian F., Bernard S., Carza$\mathrm{nig}$ a R., F o y e r C.H. The roles of redox processes in pea nodule development and senescence. Plant Cell Environ., 2005, 28: 1293-1304 (doi: 10.1111/j.1365-3040.2005.01376.x).

24. Mugli a C., Comai G., S pegazzini E., Ri c cillo P.M., Aguilar O.M. Glutathione produced by Rhizobium tropici is important to prevent early senescence in common bean nodules. FEMS Microbiol. Lett., 2008, 286: 191-198 (doi: 10.1111/j.1574-6968.2008.01285.x).

25. Ts y ga nova A.V., Ts y ganov V.E., B or is ov A.Yu., Tik honovi ch I.A., B revi n N.Dzh. Ekologicheskaya genetika, 2009, 7(3): 3-9 (in Russ.).

26. Dalton D.A., Langeberg L., Trene man N. Correlations between the ascorbateglutathione pathway and effectiveness in legume root nodules. Physiologia Plantarum, 1993, 87: 365-370 (doi: 10.1111/j.1399-3054.1993.tb01743.x).

27. M at a moros M.A., D alton D.A., Cle mente M.R., Rubio M.C., R a mos J., B e c a n a M. Biochemistry and molecular biology of antioxidants in the Rhizobia-Legume symbiosis. Plant Physiol., 2003, 133(2): 499-509 (doi: 10.1104/pp.103.025619).

28. Chang C., Damiani I., Pup p o A., Fre ndo P. Redox changes during the LegumeRhizobium symbiosis. Mol. Plant, 2009, 2: 370-377 (doi: 10.1093/mp/ssn090).

29. Marino D., Pucciariello C., Puppo A., Frendo P. The redox state, a referee of the legume-Rhizobia symbiotic game. Adv. Bot. Res., 2009, 52: 115-151 (doi: 10.1016/S00652296(10)52005-6).

30. $\mathrm{M}$ a u g h a n S., F o y e r C.H. Engineering and genetic approaches to modulating the glutathione network in plants. Physiol. Plant., 2006, 126: 382-397 (doi: 10.1111/j.1399-3054.2006.00684.x).

31. Mullineaux P.M., Rausch T. Glutathione, photosynthesis and the redox regulation of stressresponsive gene expression. Photosynth. Res., 2005, 86(3): 459-474 (doi: 10.1007/s11120-005-8811-8).

32. Frendo P., Herná nde z-Ji ménez M.J., Mat hi e u C., D u ret L., Gallesi D., Van de Sype G., Hérouart D., Puppo A.A. Medicago truncatula homoglutathione synthetase is derived from glutathione synthetase by gene duplication. Plant Physiol., 2001, 126: 1706-1715 (doi: 10.1104/pp.126.4.1706).

33. Matamoros M.A., Clemente M.R., Sato S., Asamizu E., Tabata S., Ramos J., Moran J.F., Stille r J., Gresshoff P.M., B e cana M. Molecular analysis of the pathway for the synthesis of thiol tripeptides in the model legume Lotus japonicus. Mol. PlantMicrobe Interact., 2003, 16(11): 1039-1046 (doi: 10.1094/MPMI.2003.16.11.1039).

34. Cairns N.G., Pasternak M., Wa chter A., Cobbett C.S., Meyer A.J. Matura- 
tion of Arabidopsis seeds is dependent on glutathione biosynthesis within the embryo. Plant Physiol., 2006, 141: 446-455 (doi: 10.1104/pp.106.077982).

35. Pasternak M., Li m B., Wirtz M., Hell R., Cobbett C.S., Me yer A.J. Restricting glutathione biosynthesis to the cytosol is sufficient for normal plant development. The Plant J., 2008, 53(6): 999-1012 (doi: 10.1111/j.1365-313X.2007.03389.x).

36. Moran J.F., Iturbe-Ormaetxe I., Matamoros M.A., Rubio M.C., Clemente M.R., B rewin N.J. Glutathione and homoglutathione synthetases of legume nodules. Cloning, expression, and subcellular localization. Plant Physiol., 2000, 124: 1381-1392 (doi: 10.1104/pp.124.3.1381).

37. Clemente M.R., B ustos-S an m a med P., Los cos J., J a m es E.K., Pérez R o n to m é C., Navascués J. Thiol synthetases of legumes: immunogold localization and differential gene regulation by phytohormones. J. Exp. Bot., 2012, 63: 3923-3934 (doi: 10.1093/jxb/ers083).

38. Pucciariello C., Innocenti G., Van de Velde W., Lambert A., Hopkins J., Clément M., Ponchet M., Pauly N., Goormachtig S., Holsters M., Pup p o A. (Homo)glutathione depletion modulates host gene expression during the symbiotic interaction between Medicago truncatula and Sinorhizobium meliloti. Plant Physiol., 2009, 151(3): 1186-1196 (doi: 10.1104/pp.109.142034).

39. Tada Y., S poe 1 S.H., Paje rowska-Mukhtar K., Mou Z., Song J., Wang C., $\mathrm{Z}$ u o J., D o ng X. Plant immunity requires conformational charges of NPR1 via S-nitrosylation and thioredoxins. Science, 2008, 321(5891): 952-956 (doi: 10.1126/science.1156970).

40. Peleg-Grossman S., Golani Y., Kaye Y., Melamed-Book N., Levine A. NPR1 protein regulates pathogenic and symbiotic interactions between Rhizobium and legumes and non-legumes. PLoS ONE, 2009, 4(12): 83-99 (doi: 10.1371/journal.pone.0008399).

41. Frendo P., Harrison J., Norman C., Hernández-Jiménez M.J., Van de S y p e G., Gi labert A., Pup p o A. Glutathione and homoglutathione play a critical role in the nodulation process of Medicago truncatula. Mol. Plant-Microbe Interact., 2005, 18: 254259 (doi: 10.1094/MPMI-18-0254).

42. Vernoux T., Wilson R.C., S e eley K.A., Re ichheld J.P., Muroy S., B rown S., Maughan S.C., Cobbett C.S., van Montagu M., Inzé D. The ROOT MERISTEMLESS1/CADMIUM SENSITIVE2 gene defines a glutathione-dependent pathway involved in initiation and maintenance of cell division during postembryonic root development. Plant Cell, 2000, 12: 97-109 (doi: 10.2307/3871032).

43. Diaz-Vivancos P., Dong Y.P., Ziegler K., Markovic J., Pallardy F., P e llny T.K., V e r ri e r P., F o y e r C.H. Recruitment of glutathione into the nucleus during cell proliferation adjusts whole cell redox homeostasis in Arabidopsis thaliana and lowers the oxidative defence shield. Plant J., 2010, 64: 825-838 (doi: 10.1111/j.1365-313X.2010.04371.x).

44. Diaz-Vivancos P., Wolff T., Markovic J., Pallard O.F.V., Foyer C.H. A nuclear glutathione cycle within the cell cycle. Biochem. J., 2010, 431: 169-178 (doi: 10.1042/BJ20100409).

45. Matamoros M.A., Moran J.F., Iturbe-Ormaetxe I., Rubio M.C., B e c a n a M. Glutathione and homoglutathione synthesis in legume root nodules. Plant Physiol., 1999, 121: 879-888 (doi: 10.1104/pp.121.3.879).

46. El M sehli S., Lambert A., Baldacci-Cresp F., Hopkins J., Boncompag n i E., S mit i S.A., H é rou a rt D., F r e nd o P. Crucial role of (homo)glutathione in nitrogen fixation in Medicago truncatula nodules. New Phytol., 2011, 192(2): 496-506 (doi: 10.1111/j.1469-8137.2011.03810.x).

47. Ribeiro C.W., Baldacci-Cresp F., Pierre O., Larousse M., Benyamina S., Lambert A., Hopkins J., Castella C., Cazareth J., Alloing G., Boncom$\mathrm{p}$ a g $\mathrm{ni}$ E. Regulation of differentiation of nitrogen-fixing bacteria by microsymbiont targeting of plant thioredoxin s1. Curr. Biol., 2017, 27(2):250-256 (doi: 10.1016/j.cub.2016.11.013).

48. Colville L., Sá e z C.M.B., Lew is G.P., K ran ne r I. The distribution of glutathione and homoglutathione in leaf, root and seed tissue of 73 species across the three sub-families of the Leguminosae. Phytochemistry, 2015, 115: 175-183 (doi: 10.1016/j.phytochem.2015.01.011).

49. Pasternak T., As ard H., Potters G., Jans en M.A. The thiol compounds glutathione and homoglutathione differentially affect cell development in alfalfa (Medicago sativa L.). Plant Physiol. Biochem., 2014, 74: 16-23 (doi: 10.1016/j.plaphy.2013.10.028).

50. Frendo P., Gallesi D., Turnbull R., Van de Sype G., Hérouart D., Pup p o A. Localisation of glutathione and homoglutathione in Medicago truncatula is correlated to a differential expression of genes involved in their synthesis. Plant J., 1999, 17: 215-219 (doi: 10.1046/j.1365-313X.1999.00367.x).

51. Innocenti G., Pucciariello C., Le Gleuher M., Hopkins J., de Stefano M., De1ledonne M., Puppo A., Baudouin E., Frendo P. Glutathione synthesis is regulated by nitric oxide in Medicago truncatula roots. Planta, 2007, 225: 1597-1602 (doi: 10.1007/s00425-006-0461-3).

52. Los cos J., M a t a m or os M.A., B e c a n a M. Ascorbate and homoglutathione metabolism in common bean nodules under stress conditions and during natural senescence. Plant Physiol., 2008, 146: 1282-1292 (doi: 10.1104/pp.107.114066).

53. Tsyga nov V.E., B eli mov A.A., B orisov A.Y., S a fronova V.I., Ge orgi M., 
Dietz K.J., Tikhonovich I.A. A chemically induced new pea (Pisum sativum) mutant SGECd $^{t}$ with increased tolerance to, and accumulation of, cadmium. Ann. Bot., 2007, 99(2): 227-237 (doi: 10.1093/aob/mcl261).

54. Kula y e va O.A., Ts y g a n o v V.E. Gene expression analysis of genes coding key enzymes of cadmium detoxification in garden pea symbiotic nodules. Rus. J. Genet.: Appl. Res., 2015, 5(5): 479-485 (doi: 10.1134/s207905971505007x).

55. Zh a o F.Y., Hu F., Han M.M., Z h ang S.Y., Li u W. Superoxide radical and auxin are implicated in redistribution of root growth and the expression of auxin and cell-cycle genes in cadmium-stressed rice. Russ. J. Plant Physiol., 2011, 58: 851-863 (doi: 10.1134/S102144371105027X).

56. Dalton D.A., Rus se 11 S.A., Ha nus F.J., Pas coe G.A., Evans H.J. Enzymatic reactions of ascorbate and glutathione that prevent peroxide damage in soybean root nodules. PNAS USA, 1986, 83: 3811-3815 (doi: 10.1073/pnas.83.11.3811).

57. S mirnoff N. Ascorbic acid: metabolism and functions of a multi-faceted molecule. Curr. Opin. Plant Biol., 2000, 3: 229-235 (doi: 10.1016/S1369-5266(00)80070-9).

58. Potters G., Hore mans N., Ca ubergs R.J., As ard H. Ascorbate and dehydroascorbate influence cell cycle progression in a tobacco cell suspension. Plant Physiol., 2000, 124: 1720 (doi: 10.1104/pp.124.1.17).

59. Arrigoni O., D e Tulli o M.C. Ascorbic acid: much more than just an antioxidant. Biochim. Biophys. Acta, 2002, 1569: 1-9 (doi: 10.1016/S0304-4165(01)00235-5).

60. De Tulli o M.C., Arrig o n i O. Hopes, disillusions and more hopes from vitamin C. Cell Mol. Life Sci., 2004, 61: 209-219 (doi: 10.1007/s00018-003-3203-8).

61. Whe e le r G.L., J o n e s M.A., S mirnoff N. The biosynthetic pathway of vitamin $\mathrm{C}$ in higher plants. Nature, 1998, 393: 365-369 (doi: 10.1038/30728).

62. Mat a moros M.A., Los os J., Coronado M.J., Ramos J., S a to S., Testillano P.S., T a b at a S., B e c a n a M. Biosynthesis of ascorbic acid in legume root nodules. Plant Physiol., 2006, 141: 1068-1077 (doi: 10.1104/pp.106.081463).

63. Pig no c c hi C., F o y e r C.H. Apoplastic ascorbate metabolism and its role in the regulation of cell signalling. Curr. Opin. Plant Biol., 2003, 6: 379-389 (doi: 10.1016/S1369-5266(03)00069-4).

64. Pa ndey P., S ing h J., A c hary V., R e d d y M.K. Redox homeostasis via gene families of ascorbate-glutathione pathway. Front. Environ. Sci., 2015, 3: 25 (doi: 10.3389/fenvs.2015.00025).

65. Benedito V.A., Torres-Jerez I., Murray J.D., Andirankaja A., Allen S., Kak a r K., Wandrey M., Verdier J., Zuber H., Ott T. A gene expression atlas of the model legume Medicago truncatula. Plant J., 2008, 55: 504-513 (doi: 10.1111/j.1365-313X.2008.03519.x).

66. Rahantaniaina M.S., Tuzet A., Mhamdi A., Noctor G. Missing links in understanding redox signaling via thiol/disulfide modulation: how is glutathione oxidized in plants? Front. Plant Sci., 2013, 4: 477 (doi: 10.3389/fpls.2013.00477).

67. Me ye r Y., Re i c h he ld J.P., Vig no is F. Thioredoxins in Arabidopsis and other plants. Photosynth. Res., 2005, 86: 419-433 (doi: 10.1007/s11120-005-5220-y).

68. Ramos J., Matamoros M.A., Naya L., James E.K., Rouhier N., S a to S., $\mathrm{T}$ a b at a S., B e c a n a M. The glutathione peroxidase gene family of Lotus japonicus: characterization of genomic clones, expression analyses and immunolocalization in legumes. New Phytol., 2009, 181: 103-114 (doi: 10.1111/j.1469-8137.2008.02629.x).

69. Matamoros M.A., Saiz A., Pecuelas M., Bustos-Sanmamed P., Mulet J.M., B arja M.V., Rouhier N., Moore M., James E.K., Dietz K.J., B ecana, M. Function of glutathione peroxidases in legume root nodules. J. Exp. Bot., 2015, 66(10): 29792990 (doi: 10.1093/jxb/erv066).

70. Groten K., Dutilleul C., van Heerden P.D.R., Vanacker H., Bernard S., Finke me i e r I., D i e t z K.-J., F o y e r C.H. Redox regulation of peroxiredoxin and proteinases by ascorbate and thiols during pea root nodule senescence. FEBS Lett., 2006, 580: 1269-1276 (doi: 10.1016/j.febslet.2006.01.043).

71. Alkhalfioui F., Renard M., Frendo P., Keichinger C., Myer Y., Ge 1haye E., Hirasawa M., Knaff D.B., Ritzenhaler C., Montrichard F. A novel type of thioredoxin dedicated to symbiosis in legumes. Plant Physiol., 2008, 148: 424-435 (doi: 10.1104/pp.108.123778).

72. He J., B e ne dito V.A., Wang M., Murray J.D., Z hao P.X., Tang Y., U dvard i M.K. The Medicago truncatula gene expression atlas web server. BMC Bioinformatics, 2009, 10(1): 441-456 (doi: 10.1186/1471-2105-10-441).

73. Roux B., Rodde N., Jardinaud M.F., Timmers T., Sauviac L., Cottret L., Carrère S., S allet E., C ourcelle E., Moreau S., D ebellé F. An integrated analysis of plant and bacterial gene expression in symbiotic root nodules using laser-capture microdissection coupled to RNA sequencing. Plant J., 2014, 77(6): 817-837 (doi: 10.1111/tpj.12442).

74. L e e M.-Y., Shin K.-H., Ki m Y.-K., S uh J.-Y., Gu Y.-Y., K i m M.-R., H u r Y.-S., S o n O., K i m J.-S., S o ng E. Induction of thioredoxin is required for nodule development to reduce reactive oxygen species levels in soybean roots. Plant Physiol., 2005, 139: 1881-1889 (doi: 10.1104/pp.105.067884). 
75. Edwards E., Dix o n D.P., Wa lb ot V. Plant glutathione S-transferases: enzymes with multiple functions in sickness and in health. Trends Plant Sci., 2000, 5: 193-198 (doi: 10.1016/S1360-1385(00)01601-0).

76. Dalton D.A., Boniface C., Turner Z., Lindahl A., Kim H.J., Jelinek L., Govind a rajulu M., Finger R.E., Tay lor C.G. Physiological roles of glutathione S-transferases in soybean root nodules. Plant Physiol., 2009, 150: 521-530 (doi: 10.1104/pp.109.136630).

77. McGonigle B., Ke eler S.J., Lau S.-M.C., Koeppe M.K., O'Ke efe D.P. A genomics approach to the comprehensive analysis of glutathione S-transferase gene family in soybean and maize. Plant Physiol., 2000, 124: 1105-1120 (doi: 10.1104/pp.124.3.1105).

78. Rubio M.C., James E.K., Clemente M.R., Bucciarelli B., Fedorova M., Vance C.P., Becana M. Localization of superoxide dismutases and hydrogen peroxide in legume root nodules. Mol. Plant-Microbe Interact., 2004, 17: 1294-1305 (doi: 10.1094/MPMI.2004.17.12.1294).

79. Wis ni e w s ki J.P., R a t h b u n E.A., K n ox J.P., B re wi n N.J. Involvement of diamine oxidase and peroxidase in insolubilization of the extracellular matrix: implications for pea nodule initiation by Rhizobium leguminosarum. Mol. Plant-Microbe Interact., 2000, 13: 413-420 (doi: 10.1094/MPMI.2000.13.4.413).

80. Rubio M.C., B e c a na M., S a to S., Ja mes E.K., T abata S., S paink H.P. Characterization of genomic clones and expression analysis of the three types of superoxide dismutases during nodule development in Lotus japonicus. Mol. Plant-Microbe Interact., 2007, 20: 262-275 (doi: 10.1094/MPMI-20-3-0262).

81. Tejera N.A., Ca m p os R., S a n j u á n J., L l u c h C. Nitrogenase and antioxidant enzyme activities in Phaseolus vulgaris nodules formed by Rhizobium tropici isogenic strains with varying tolerance to salt stress. J. Plant Physiol., 2004, 161: 329-338 (doi: 10.1078/0176-1617-01050).

82. Jebara S., Jebara M., Limam F., Aouani M.E. Changes in ascorbate peroxidase, catalase, guaiacol peroxidase and superoxide dismutase activities in common bean (Phaseolus vulgaris) nodules under salt stress. J. Plant Physiol., 2005, 162: 929-936 (doi: 10.1016/j.jplph.2004.10.005).

83. Furlan A.L., Bianucci E., del Carmen Tordable M., Castro S., Dietz K.J. Antioxidant enzyme activities and gene expression patterns in peanut nodules during a drought and rehydration cycle. Funct. Plant Biol., 2014, 41(7): 704-713 (doi: 10.1071/FP13311).

84. G o go r c e n a Y., I t u rbe - Orma e t x e I., Es c u redo P.R., B e c a n a M. Antioxidant defenses against activated oxygen in pea nodules subjected to water stress. Plant Physiol., 1995, 108: 753-759 (doi: 10.1104/pp.108.2.753).

85. Porcel R., B a re a J.M., Ruiz-Lozano J.M. Antioxidant activities in mycorrhizal soybean plants under drought stress and their possible relationship to the process of nodule senescence. New Phytol., 2003, 157: 135-143 (doi: 10.1046/j.1469-8137.2003.00658.x).

86. S c a nd ali os J.G., Gu a n L., P o lid or os A.N. Catalases in plants: gene structure, properties, regulation, and expression. In: Oxidative stress and the molecular biology of antioxidant defense. J.G. Scandalios (ed.). Cold Spring Harbor Press, NY: 343-406.

87. J a met A., Sigaud S., Van de Sype G., Puppo A., Hé rouart D. Expression of the bacterial catalase genes during Sinorhizobium meliloti-Medicago sativa symbiosis and their crucial role during the infection process. Mol. Plant-Microbe Interact., 2003, 16(3): 217-225 (doi: 10.1094/MPMI.2003.16.3.217).

88. De Lorenzo C., Luc as M.M., Vivo A., de Felipe M.R. Effect of nitrate on peroxisome ultrastructure and catalase activity in nodules of Lupinus albus L. cv. Multolupa. J. Exp. Bot., 1990, 41: 1573-1578 (doi: 10.1093/jxb/41.12.1573).

89. Kl a p h e c k S. Homoglutathione: isolation, quantification and occurrence in legumes. Physiol. Plant., 1988, 74(4): 727-732 (doi: 10.1111/j.1399-3054.1988.tb02044.x).

90. Jiménez-Bremont J.F., Marina M., de la Luz Guerrero-González M., Rossi F.R., Sánchez-Rangel D., Rodríguez-Kess le r M., Ruiz O.A., Gárriz A. Physiological and molecular implications of plant polyamine metabolism during biotic interactions. Front. Plant. Sci., 2014, 5: 95 (doi: 10.3389/fpls.2014.00095).

91. It u rbe-Ormaetxe I., Mat a moros M.A., Rubio M.C., Dalton D.A., B ec an a M. The antioxidants of legume nodule mitochondria. Mol. Plant-Microbe Interact., 2001, 14(10): 1189-1196 (doi: 10.1094/MPMI.2001.14.10.1189). 